\title{
Que seja moderna enquanto dure: a apropriação da fotografia amadora brasileira
}

\section{May it be modern while it lasts: the appropriation of amateur Brazilian photography}

\section{Lucas Mendes Menezes}

Université Paris 1 Panthéon Sorbonne

\section{Resumo}

O processo de reconhecimento institucional da geração de fotógrafos amadores brasileiros dos anos 1950 e 1960 se realizou mediante diferentes empreitadas. Se as mostras de Thomaz Farkas (Museu de Arte Moderna de São Paulo, em 1949) e Geraldo de Barros (Museu de Arte de São Paulo, em 1951) foram fundamentais para a legitimação da fotografia como prática artística no Brasil, apenas nos anos 1980 esse percurso alcançou a dimensão institucional. Em paralelo, assistiu-se também à entrada de algumas dessas imagens no mercado da arte, através de representação de galerias no Brasil e no exterior. Nos anos 2000 , graças a políticas de doação e aquisição, essa geração de fotógrafos passou a compor vários dos principais acervos fotográficos do país. No caso brasileiro, os últimos 30 anos de trabalhos em torno da fotografia conseguiram estabelecer a geração dos fotógrafos amadores do pós-guerra como algumas das principais personalidades do meio no país.

Palavras-chave: Fotografia moderna; Arte e fotografia; Fotografia amadora.

\section{Abstract}

The process of institutional recognition of the pictures produced by Brazilian amateur photographers in the 1950s and 1960 s was carried out through different fronts. If the exhibitions of Thomaz Farkas (São Paulo's Modern Art Museum, in 1949) and Ceraldo de Barros (São Paulo's Art Museum, in 1951) were fundamental for the legitimization of photography as an artistic practice in Brazil, only in the 1980s they reach an institutional level. In parallel, we also saw the entry of some of these images in the artmarket, through representation of galleries in Brazil and abroad. In the 2000s, thanks to donation and acquisition policies, this generation of photographers became part of several of the country's main photographic collections. In this way, the objective is to discuss the different cycles of appropriation to which these images were submitted, as well as to highlight the interpretative paths and the main elements mobilized in the construction of the "modern generation" of Brazilian photography.

Keywords: Modern photography; Art and Photography; Amateur Photography. 


\section{Artigos e Ensaios na atuafidade: relaçôes praticadas}

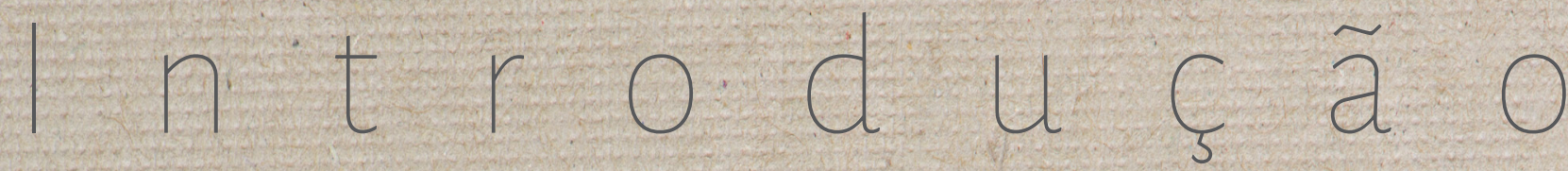

m maio de 2016, o Museu de Arte Moderna de Nova York, mediante iniciativa da curadora Sarah Meister, adquiriu um conjunto de vinte e oito fotografias de autoria de Paulo Pires, José Yalenti, Ademar Manarini, Eduardo Salvatore, Marcel Ciró e Certrude Austchul, todos membros do Foto Cine Clube Bandeirante de São Paulo. Essas imagens se somaram àquelas dos também membros do clube paulistano: Thomaz Farkas (resultado de uma doação do artista ao museu no fim da década de 1940), Geraldo de Barros (adquiridas em 2006 e 2013) e Gaspar Casparian (adquiridas em 2015). Todas essas imagens foram produzidas entre as décadas de 1940 e 1960 e, originalmente, fizeram parte do circuito de exposições de fotografias amadoras do período.

Segundo Meister (2016), essas aquisições fazem parte do conjunto de iniciativas que visa ampliar a representatividade da fotografia latino-americanà no acervo do museu e envolveu também a compra de obras de artistas argentinos, colombianos, peruanos e venezuelanos, assim como de artistas contemporâneos brasileiros como Cao Guimarães, Rosangela Rennó e Vik Muniz. Contudo, as imagens dos membros do Bandeirante representam, tanto pela sua quantidade, mas também pela sua coesão, uma coleção singular. Neste sentido, o objetivo deste texto é discutir os diferentes ciclos de apropriação a que essas imagens foram submetidas, assim como evidenciar os caminhos interpretativos e os principais elementos mobilizados na construção da "geração moderna" da fotografia brasileira.

O estudo em torno dessa geração envolve, em um primeiro momento, a atenção às condições de produção, quais sejam: o desenvolvimento do fotoclubismo no Brasil e a realização dos primeiros salões; o contexto sócio-artístico-cultural nacional; e a entrada da fotografia amadora em espaços expositivos e museus no país. Segundo Costa e Rodrigues (COSTA \& RODRIGUES, 1995), o desenvolvimento de uma classe média brasileira, no Pós-Guerra, proporcionou as bases para a expansão da prática fotoclubista - já bastante difundida nos setores médios norte-americanos e europeus - no país. Os autores foram ainda os primeiros a discutir, em um maior nível de profundidade, os alcances de uma geração de fotógrafos paulistanos que teria revolucionado a fotografia brasileira. Da interpretação do trabalho dos "pioneiros" e dos membros da chamada "Esco-

1 José Yálenti, Thomaz Farkas, Geraldo de Barros e German Lorca. 
la Paulista"z - todos filiados ao Foto Cine Clube Bandeirante de São Paulo - estava lançada a base para a consolidação da geração moderna da fotografia brasileira, efetivada em oposição aos preceitos de uma prática fotográfica acadêmica, e sua deferência aos parâmetros da pintura dos salões, bastante difundidos nas primeiras agremiações do gênero no Brasil.

Apesar de apresentar peculiaridades importantes, que dizem respeito tanto ao processo de formação, quanto guarda e promoção dos seus acervos, o caso brasileiro não pode ser tomado de maneira isolada. Primeiramente, porque o fotoclubismo foi um fenômeno internacional por excelência. Para tanto, é preciso uma definição mais clara em torno desse gênero de produção fotográfica. Em um segundo momento, será pertinente discutir as iniciativas e parcerias peculiares que fizeram com que a fotografia passasse a ser exibida em espaços de promoção e legitimação artística. Apesar de pontuais e esporádicas, elas conformaram um importante passo para o reconhecimento da importância da imágem fotográfica no Brasil, consagrando uma prática - ainda majoritariamente amadora e que, em grande parte do globo, era ainda marginalizada - como uma atividade artística. Esses dois primeiros percursos conformarão a base para a dicussão em torno dos variados ciclos de apropriação dessa geração pioneira, além das as estratégias - interpretativas, institucionais, narrativas e, porque não, comerciais - que envolveram esse processo. $A$ análise, a partir dos dados levantados pela pesquisa, terá como foco mapear as características marcantes, mas também permanecer buscará apreender a recorrência de "fenômenos aparentemente negligenciáveis" (CINZBURC, 1991) que, voluntariamente ou involuntariamente, podem apresentar características fundamentais a respeito de sua composição. Eé justamente nesse exercício que repousa a peculiaridade do olhar do historiador sobre as relações entre arte e fotografia.

\section{Prática fotográfica amadora}

Desde o pioneirismo da Kodak no fim do século XIX, os avanços tecnológicos em fotografia permitiam que pessoas sem o mínimo conhecimento do processo pudessem realizar fotografias: bastava o apertar de um botão. Em processo paralelo, praticantes mais exigentes da fotografia, tanto do ponto de vista técnico quanto estético, passaram a se reunir em agremiações na Europa e nos Estados Unidos. Esses coletivos, posteriormente convencionados como fotoclubes, variavam segundo êxito, proporção e alcance, e se distinguiam tanto dos amadores ordinários, quanto dos fotógrafos profissionais que, trabalhando em estúdios ou a serviço de atividades técnicas, representavam uma prática tecnicista, portanto quase operária da fotografia.

2 Eduardo Salvatore, Marcel Giró, Roberto Yoshida, Gertrudes Altschul, Ademar Manarini, Gaspar Gasparian, Ivo Ferreira da Silva e João Bizarro Nave Filho. 
Para além das oposições, de maneira geral, os fotoclubes também possuíam em comum a missão de promover a perspectiva artística da fotografia. Essa missão se traduzia em uma busca por legimitidade que, muitas das vezes, implicou no desenvolvimento de processos de composição, intervenção manual e técnicas que aproximavam a fotografia de suportes mais tradicionais como a pintura e a escultura. A fotografia que até então era exposta em feiras e exposições universais, sobretudo pelo aspecto da curiosidade técnica, passava a ganhar autonomia enquanto criação artística. Neste contexto, a atuação de entidades pioneiras como a Royal Photographic Society e a Société Française de Photographie, respectivamente criadas em 1853 e 1854, foi essencial para a realização das primeiras mostras e salões fotográficos.

No Brasil, é possível mapear algumas iniciativas de associação de fotógrafos amadores desde o início do século XX. Em Arte e Fotografia: o movimento pictorialista no Brasil, Maria Teresa Villela Bandeira de Mello (1998) apresenta um histórico das primeiras manifestações da prática fotográfica artística amadora no território brasileiro. Para além das efêmeras experiências das exposições coletivas do Sploro Photo-Club em Porto Alegre em $1903^{3}$ e do Photo-Clube do Rio de Janeiro em 19044, Mello destaca o Photo Clube Brasileiro5, criado em 1923 no Rio de Janeiro, como a primeira instituição do gênero a se consolidar no país. Dentre outras realizações ${ }^{6}, 0$ clube foi responsável pela organização do Primeiro Salão Brasileiro de Arte Fotográfica em 1940, primeiro evento do gênero em uma escala nacional?

Em São Paulo, a Sociedade Paulista de Fotografia foi criada em 1926, atuando de maneira esporádica até o incício da década de 1930. Apenas em 1939, com a criação do Foto Clube Bandeirante ${ }^{8}$, um clube de fotógrafos amadores dá início a uma trajetória de atuação contínua na capital paulista.

3 O Sporo Photo-Club organizou, em parceria com o jornal Gazeta do Commercio, uma exposição coletiva em 1903, fórmada por fotografias, mas também outras expressões artísticas.

4 A exposição "Photo-Clube - Exposição 1904" reuniu trabalhos dos artistas Oscar Teffé, Sílvio Bevilacqua, Barroso Neto e Cuerra Durval.

5 Ainda na década de 1930 adota a grafia: Foto Clube Brasileiro.

6 O Foto Clube Brasileiro publicou a revista Photogramma entre 1926 e 1931, além de já organizar salões fotográficos locais com regularidade em paralelo.

7 Todavia, dos sessenta fotógrafos que apresentaram trabalhos na ocasião do evento, trinta e sete eram da cidade do Rio de Janeiro. Além disso, apenas onze dos então vinte estados da Federação estiveram representados na ocasião do evento: Bahia (1 fotógrafo, 5 fotografias), Ceará (1 fotógrafo, 3 fotografias), Minas Cerais ( 5 fotógrafos, 12 fotografias), Paraná (1 fotógrafo, 1 fotografia), Pernambuco (1 fotógrafo, 2 fotografias), Piauí (1 fotógrafo, 1 fotografia), Rio Grande do Norte (1 fotógrafo, 1 fotografia), Rio Grande do Sul (1 fotógrafo, 5 fotografias), Estado do Rio de Janeiro (2 fotógrafos, 8 fotografias), Santa Catarina, (2 fotógrafos, 8 fotografias), São Paulo (7 fotógrafos, 22 fotografias). Para além de Minas Gerais e São Paulo, as contribuições dos demais estados não pareceu expressiva, totalizando um contingente de 26 fotografias versus as 101 imagens expostas pelos fotógrafos cariocas. Além dos fotógrafos, duas outras entidades contribuíram com fotografias para a exposição: $\mathrm{O}$ Estúdio MOB da cidade do Rio de Janeiro (2 fotografias) e o Serviço de Propaganda do Estado do Rio de Janeiro ( 4 fotografias).

8 Adota a nomenclatura Foto Cine Clube Bandeirante na década seguinte. 
De maneira geral, todo fotoclube realizava, em frequência anual ou bienal, exposições que contavam com a participação de agremiações do seu próprio país, mas também do exterior, o que consolidava um circuito de trocas de imagens de grandes proporções. Com o avanço da Segunda Guerra Mundial, a cidade de São Paulo que já recebera um volume importante de imigrantes entre o fim do século XIX e início do século XX, tornou-se ainda mais internacional. O Foto Cine Clube Bandeirante, por sua vez, passa a organizar seu Salăo Internacional oficialmente9 a partir de 1946. Em processo paralelo, os trabalhos dos principais expositores paulistas também passavam a figurar em outros salões internacionais, principalmente em solo europeu.

Uma das funções do Boletim ${ }^{10}$ publicado pelo fotoclube paulistano era justamente difundire repercurtir as ações do clube e dos seus associados. Segundo a publicação, em 1946, os fotógrafos paulistanos tiveram 378 trabalhos admitidos em 19 salões internacionais realizados por clubes no Brasil, Argentina, Chile, EUA, Espanha, Inglaterria e Austrália (BOLETIM, jan. 1947). No Imagem 1 - Fotografia de José Oiticica (1953). ano seguinte, o periódico (BOLETIM, mar. 1948) registrou o aceite de 581 fotografias aceitas, em 27 "certames"11.

Em convocatória à adesão enviada ao clube, Maurice Van de Wyer - fotógrafo amador belga e presidente da Fédération Internationale d'Art Photographique (FIAP) - declarou o FCCB como a "sociedade mais potente da América do Sul” (BOLETIM, 1950 , p. 7). A FIAP, instituição criada na Suiça em 1950 , inspirada pela consolidação de órgãos de cooperação internacional em todo mundo no Pós-Cuerra, tinha como meta estimular o intercâmbio artístico entre os países, assim como estabelecer parâmetros internacionalmente reconhecidos para a realização de salões e o julgamento de imagens.

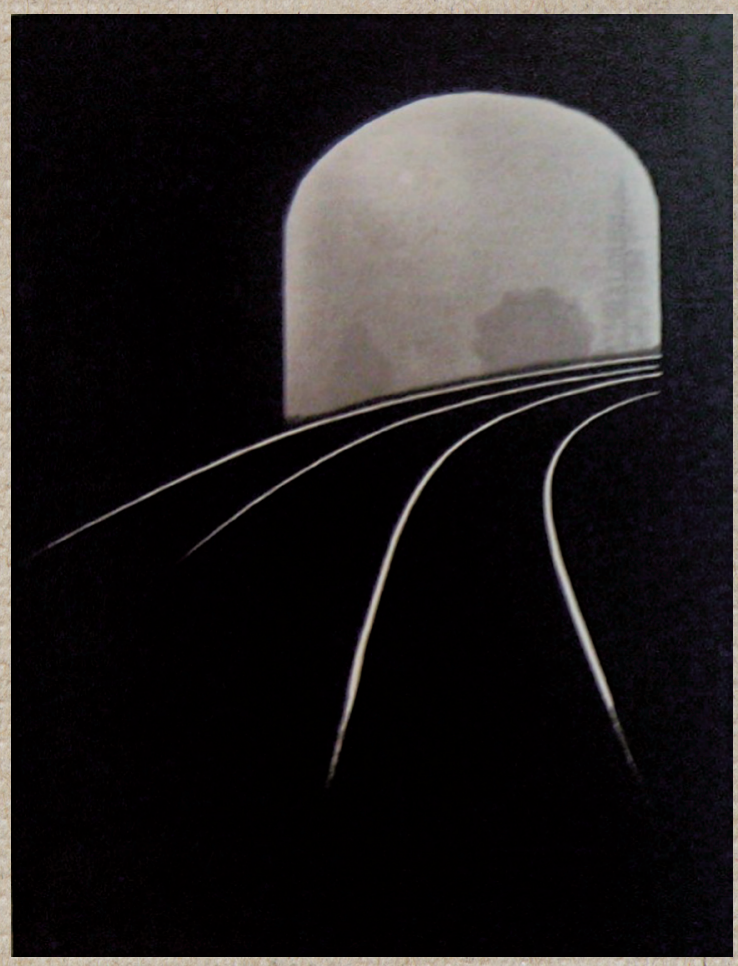

Fonte: Photograms of the year (1953).

9 Na realização do Primeiro Salão Paulista de Arte Fotográfica em 1942, o FCCB contou com a participação de fotógrafos de diversas regisões do país, mas também ofereceu ao público a seção "BOA VISINHANÇA", que acolheu 18 trabalhos de fotógrafos de dois fotoclubes argentinos.

10 Publicado regularmente a partir de 1946 pelo FCCB.

11 Expressão utilizada no texto e referida rotineiramente no contexto da discussão sobre os salões, o gue detona o caráter de competição desse gênero de evento para a comunidade de fotoclubes. 
Apesar de jovem, a FIAP conseguiu exercer um relevante papel aglutinador, sendo responsável tanto por ações diretas, como a realização de bienais internacionais a partir de 1950, mas também através da regulamentação de mostras e credenciamento de autores ao redor do mundo. Neste contexto, a participação brasileira era, de certa maneira, irregular ${ }^{12}$. Por outro lado, entidades tradicionais como a Royal Photographic Society e a Société Française de Photographie, através de suas publicações, mas também mediante a organização de mostras (Imagem 1), permaneciam como

Imagem 2 - Vision du Nord Brésilien (1946), de Gaspar Casparian.

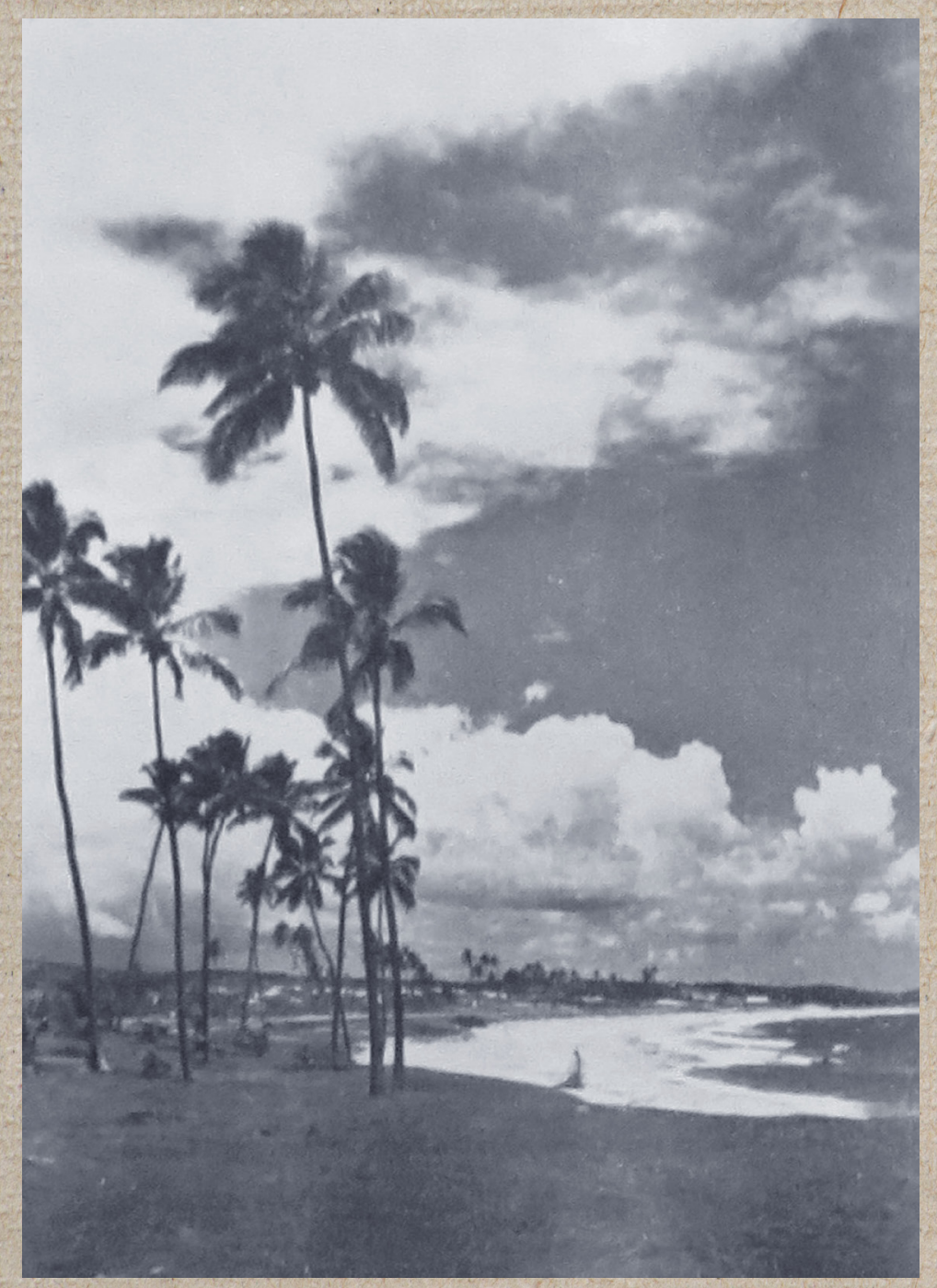

Fonte: IV Salão Capixaba de Arte Fotográfica (1951). importantes referências para a comunidade de fotoclubes do período.

A presença brasileira no Salon International d'Art Photographique da Société Française de Photographie foi ainda mais frequente. $O$ salão foi realizado regularmente desde o início do século $X X$, à exceção dos anos contidos entre 1939 e 1945 , até 1953 . A sua retomada em 1946 coincide também com a primeira participação brasileira no evento. Nas palavras de Daniel Masclet $^{13}$, principal comentador dos salões parisienses do período, se no salão de 1946 (Imagem 2) os fotógrafos brasileiros "mostraram ricas e típicas imagens com uma forte coloração local", no ano seguinte (Imagem 3) eles enviaram apenas, "cópias desimportantes" (MASCLET, 1947, p. 157).

O Salão de 1950 contou com o envio de 40 imagens hors-concours produzidas por 27 membros do Foto Cine Clube Bandeirante, o que contribuiu para a maior participação brasileira no evento ( 53 fotografias, entre 467 expostas no total), que ainda contaria com participação de outros 6 fotógrafos oriundos de agremiações do Rio de Janeiro.

12 Para tanto, contribuíam tanto a distância em relação às agremiações localizadas na Europa e nos EUA, mas também o sistema de representação nacional escolhido pela FIAP. Apesar dos esforços, que envolveram visitas do próprio Van de Wyer ao Brasil durante toda a década de 1950, a Confederação Brasileira de Fotografia só se efetivaria em 1958. 13 Membro do Groupe des XV, um coletivo formado por fotógrafos como Robert Doisneau, Willy Ronis e Lucien Lorelle. 
Em 1951, o discurso de Masclet (1951, p.249) retoma o tom amargo de algumas de suas críticas dos anos anteriores. O motivo de seu descontentamento é a sensação de crise generalizada do meio fotógrafo amador e a consequente falta de "vida, interesse e de novidades". Para o autor, os "salonistes" não se renovam e expõem seu "produto habitual: a 'Bela Foto de Salon". Além disso, Masclet aponta para o fato de que grande parte dos mais reconhecidos fotógrafos do período não enviavam fotografias aos salões seja por receio de serem muito "modernos", "diferentes" ou mesmo de serem recusados. Masclet insiste que o salão de Paris não apresenta : Ansel Adams, Renger-Patzsch, Mortensen, Meerson, Cartier-Bresson, Avedon, Man-Ray, Toni Frissel, Winquist, Donzelli, Bourke-White, Lazi ou Cecil Beaton: Em contraponto, ele menciona o sucesso que Edward Weston alcançou em Paris com sua exposição na Galerie Kodak.

Imagem 3-Hiver (1946), de Eduardo Salvatore.

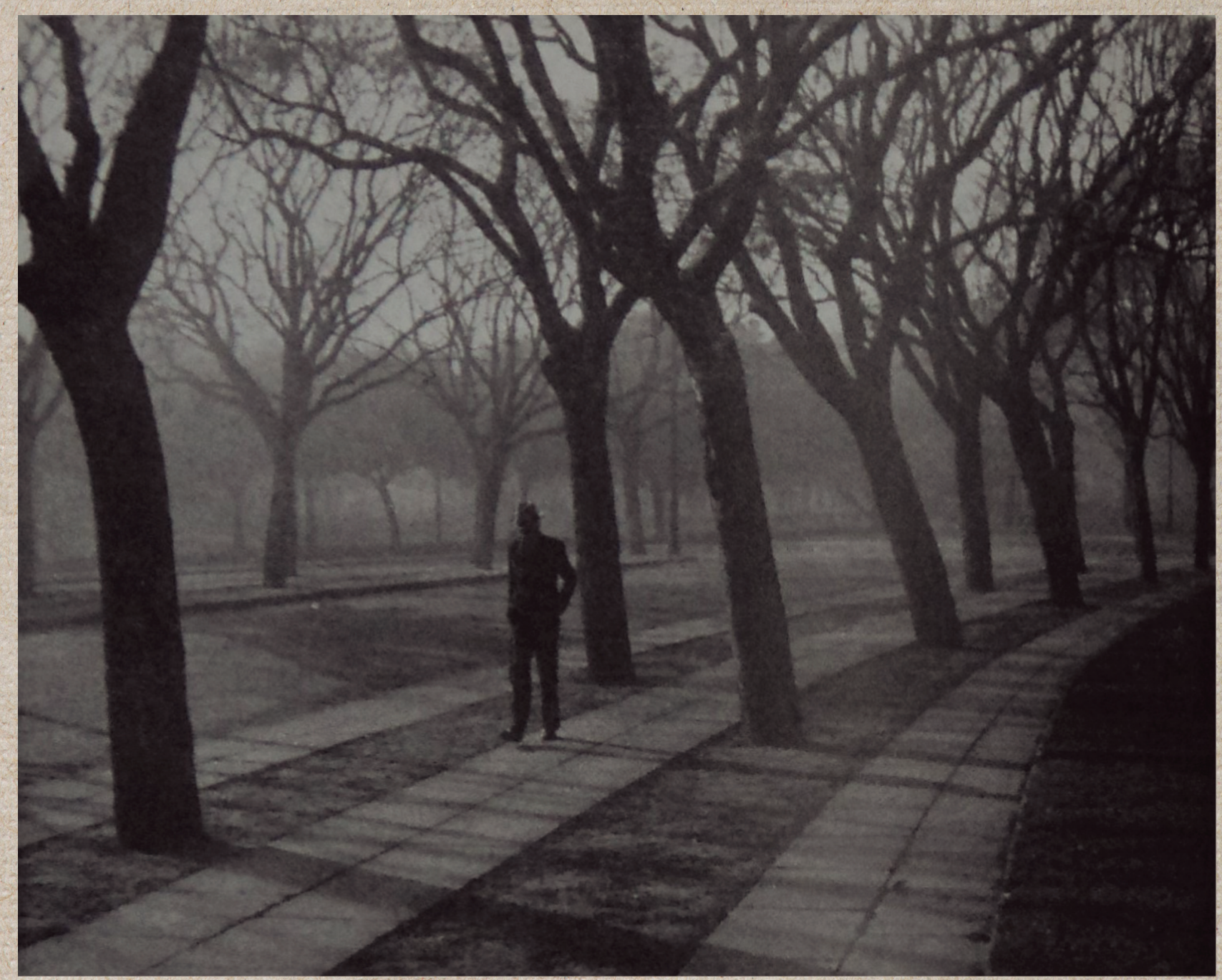

Fonte: Il Salão Nacional de Arte Fotográfica - FCC do Recife (1955).

Para Masclet, o nível havia baixado entre os brasileiros no salão de 1951: "E como eles não nos mostram nem o Amazonas, nem a floresta virgem, nem os índios, nem mesmo um jacaré ou 
um periquito!"14. A crítica de Masclet reforça a impressão de que a expectativa em torno da produção fotográfica brasileira do período estava relacionada muito mais à representação do exótico e de imagens típicas do Brasil, do que propriamente um interesse pelas questões artísticas que caracterizavam o conjunto exibido pelo país. Ou seja, um interesse mais documental, do que artístico. Ao todo, 52 fotografias foram enviadas para a participação no salão, das quais 21 foram aceitas para exposição. Contudo, são justamente as fotografias enviadas em 1951 pelos fotoclubes brasileiros que conformarão a base da coleção de fotografias brasileiras ${ }^{15}$ mantida atualmente pela SFP.

Se 1947 foi marcado pela intensa participação do FCCB em exposições no exterior, este foi também um período de desenvolvimento do seu próprio salão internacional. Segundo relatório da diretoria, publicado no Boletim (1947, p. 9), o V Salão (1946) teria "atraído a maior colaboração já alcançada por qualquer salão sul-americano". Ao todo 19 países foram representados e 0 envio internacional foi responsável por mais da metade das fotografias enviadas para julgamento.

Um dos relatos mais interessantes sobre a realização dos salões internacionais do FCCB foi publicado na ocasião da nona edição, realizada em outubro de 1950. José Oiticica Filho (BOLETIM, 1950) - que voltava de uma temporada nos EUA - optou por comentar o trabalho dos fotógrafos brasileiros aceitos e premiados durante a mostra realizada na Galeria Prestes Maia. Seu ponto de partida era a compreensão da arte "como uma atividade humana cujo propósito é a transmissão a outros dos mais altos e melhores sentimentos atingidos pelo homem". Em seu texto, ele vai dar atenção, em um primeiro momento, aos "chamados modernistas ou 'pesquisadores'16". Os primeiros trabalhos comentandos por Oiticica Filho são as fotografias de German Lorca. Ao mesmo tempo em que elogia a fotografia Le diable au corps ${ }^{17}$; uma imagem solarizada, mas que "tem tudo e algumas coisas mais de um bom quadro pictórico", o autor refuta o aceite de duas outras imagens de Lorca, principalmente pelo caráter supostamente de reportagem que uma das imagens parecia trazer.

JOF também vai também comentar os trabalhos apresentados pelo juri: Francisco Albuquerque, Angelo Nuti, Eduardo Salvatore, Jacob Polacow e José Yalenti.

14 "Et comment se fait-il ne nous présente ni l'Amazone, ni la forêt vierge, ni les Indiens, pas même un caîman ou perroquet!" (tradução livre). (MASCLET, 1951)).

15 A coleção de fotografias brasileiras da Société Française de Photographie foi formada a partir das imagens enviadas para a participação no Salão de 1951, mas também por aquelas que foram exibidas em 1960, na ocasião da mostra sobre fotografia brasileira realizada na Galeria Montalembert da SFP.

160 último termo o autor destaca ter aprendido durante sua convivência no FCCB. Nesse grupo o autor inclui os artistas: Cerman Lorca, Gaspar Gaparian e Aldo,Sousa e Lima.

17 A fotografia fez parte do envio hors-concours realizado pelos membros do FCCB para o Salão de Paris em 1950. 


\section{"FOTOGRAFIAS, Dr. Pfeiffer!" 18}

Um dos aspectos mais singulares da trajetória do clube de fotógrafos amadores da capital paulista foi a sua aproximação com espaços expositivos e museus, em atividade que se efetivou paralela, mas também transversalmente, ao cotidiano da agremiação.

Inaugurada em junho de 1949 no "Salão Pequeno" do recém-criado Museu de Arte Moderna de São Paulo, a mostra Estudos Fotográficos, de Thomaz Farkas, foi o primeiro resultado do trabalho da comissão orientadora da seção de fotografia ${ }^{19}$ do MAM, formada exclusivamente por membros do FCCB: o próprio Farkas, Benedito Duarte, Eduardo Salvatore e Francisco Albuquerque. Em artigo (BOLETIM, 1949), publicado na revista do FCCB no mês da inauguração da mostra, é ressaltado o fato de Farkas tem ingressado no clube quando ainda era adolescente e que movido por uma pesquisa em torno de "ritmos mais candentes e dinâmicos", buscou ângulos arrojados e composições resultantes do seu "temperamento cerebral". A exposição contou com o projeto expográfico de Jacob Rutchi e Miguel Forte, assim como Farkas, recentemente regressos de viagem aos EUA.

A mostra Fotoformas, do artista Ceraldo de Barros, foi realizada em 1951 no Museu de Arte de São Paulo. Nesse processo, a pesquisa do artista, que já se desenvolvia em torno de composições abstratas, começou a apresentar um "caráter predominantemente construtivo, muito embora o artista não tivesse um projeto teórico que norteasse a sua pesquisa." (COSTA \& RODRICUES, 1995, p. 52) A expografia da mostra era resultado tanto do esforço do artista, que privilegiou aspectos geométricos e o uso estruturas tridimensionais, quanto do projeto museográfico inovador do MASP, como por exemplo, o uso de cilindros verticais na montagem das mostras temporárias.

Geraldo de Barros também seria um dos responsáveis pela participação de fotógrafos do FCCB na II Bienal de São Paulo em 1953. Apesar de empreendida de improviso - mediante a desistência de algumas representações estrangeiras - a participação dos fotógrafos bandeirantes teve uma boa repercussão, tanto junto aos organizadores, quanto à crítica em torno da Bienal. As fotografias foram escolhidas pelo próprio Geraldo de Barros (BARROS, 1954, p. 12), além de Eduardo Salvatore, José Yalenti e Ademar Manarini, todos membros do FCCB, através da consulta às gavetas do clube, abastecidas para o envio coletivo para participação em salões e exposições no Brasil e no exterior.

18 Trecho do relato escrito por Ceraldo de Barros (1954, p. 12) sobre o processo que garantiu a participação dos fotógrafos do FCCB na II Bienal de São Paulo em 1953.

190 MAM organizaria, em 1952 e 1954, duas exposições individuais de outros dois membros do FCCB de São Paulo, respectivamente German Lorca e Ademar Manarini. 
Artigos e Ensaios

Fotografia, Arte e História

na atualidade: relações praticadas

Mas de que maneira o caso brasileiro se relaciona com empreitadas precedentes e o que ele apresenta de original? O reconhecimento institucional da fotografia artística se efetivou a partir de um conjunto importante de variáveis. A atuação do Camera Club em New York, fundado por Alfred Stieglitz no início do século XX, é emblemática tanto pela publicação da revista Camera Work ${ }^{20}$ em 1903, mas, também por estar. na origem da criação da Caleria 291, ativa entre 1908 e 1917. Ao exibir tanto cópias fotográficas, quanto trabalhos dos mais renomados artistas das vanguardas europeias do período, a galeria teve um papel embrionário para a elevação da fotografia ao nível de uma prática artística. Prova disso foi o papel que um dos seus idealizadores, Edward Steichen, exerceu como Diretor de Fotografia do Museu de Arte Moderna de Nova York entre as décadas de 1940 e 1960.

O caso brasileiro guarda semethanças com essas duas realidades; é impossivel negar o papel de referência que alguns artistas e instituições, tanto europeus quanto americanos, exerceram no imaginário nacional. Contudo, o ritmo dos acontecimentos, a intensidade das aproximações e distanciamentos, além da atividade peculiar de alguns artistas, colecionadores e incentivadores no Brasil vão dar contornos próprios à relação entre arte e fotografia.
O MoMA foi uma entidade pioneira no que diz respeito ao trato com a fotografia. A organização da mostra Photography 1839-193721 em 1937, por Beaumont Newhall, é uma prova definitiva dessa realidade. A exposição, que antecipou a criação do Setor de Fotografia do museu em 1940 (DOBRANSZKY, 2008), ocupou os quatro pavimentos do museu e foi antecipada por um processo de pesquisa que incluiu viagens à França e à Inglaterra.

Para a conformação da seção "Fotografia Contemporânea”, Edward Weston e Ansel Adams foram, entre os norte-americanos, os principais conselheiros de Newhall e, além de cederem cópias de suas imagens, indicaram uma série de trabalhos de fotógrafos ao curador. Na Europa, Lazlo Moholy-Nagy foi referência para Newhall, tendo cedido inclusive dezesseis fotografias de sua autoria que continham experimentações com fotogramas e também imagens coloridas. Ainda compunham a mostra, entre outras personalidades, Man Ray, Paul Strand e Brassaï.

No contexto europeu da primeira metade do século $X X$, a relação entre a fotografia e as artes de vanguar-

20 Grande responsável pela publicização da straight photography norte-americana.

21 A exposição foi acompanhada por um catálogo de autoria de Newhall (1937) que mais tarde daria origem ao seu célebre e pioneiro livro: History of Photography (1949).

108

Resgate-Rev. Interdiscip. Cult., Campinas, v. 26, n. 2 [36], p. 99-116, jul./dez. 2018-e-ISSN: 2178-3284 
da é ainda mais orgânica, basta ver o espaço ocupado pela fotografia em movimentos como o dadaísmo e o surrealismo. Em Nova York, as primeiras iniciativas de exposição de fotografias como objetos artísticos, num contexto exterior ao circuito de salões de fotoclubes, foram empreendidas mediante a associação destes trabalhos com obras de arte de vanguarda. $\mathrm{O}$ caso brasileiro guarda semelhanças com essas duas realidades; é impossível negar o papel de referência que alguns artistas e instituições, tanto europeus quanto americanos, exerceram no imaginário nacional. Contudo, o ritmo dos acontecimentos, a intensidade das aproximações e distanciamentos, além da atividade peculiar de alguns artistas, colecionadores e incentivadores no Brasil vão dar contornos próprios à relação entre arte e fotografia. Por aqui, quase tudo se passou entre o fim da década de 1940 e o início da década de 1950. Eé justo dizer que mesmo as iniciativas pioneiras não foram acompanhadas por políticas efetivas de formação e guarda de acervos; na medida em que não havia um projeto definido em torno da fotografia artística. É verdade também que, nas décadas seguintes, a diluição das fronteiras entre os diferentes meios na produção da arte contemporânea brasileira pode fazer essa premissa parecer inválida. Contudo, os contínuos esforços de aquisição e promoção de acervos em torno dessa geração de fotógrafos brasileiros nas últimas décadas são os principais indícios de que, de fato, havia uma importante lacuna a ser preenchida.

\section{Apropriações}

Em 1981, a Fundação Nacional de Artes (Funarte) organizou a exposição Hermínia de Mello Nogueira Borges - Fotografias na galeria localizada em sua sede no Rio de Janeiro. A mostra foi montada a partir do acervo pessoal da própria fotógrafa, antiga secretária do Foto Clube Brasileiro e esposa do presidente da agremiação. Hermínia teve uma atuação de destaque em salões no país e no exterior, produzindo fotografias durante décadas e acumulando uma importante coleção, não apenas de imagens suas, mas também de seu marido e outros colegas de clube. Dois anos depois, na mesma galeria, seria realizada a mostra José Oiticica Filho: a ruptura da fotografia nos anos 50, resultado do trabalho de pesquisa do curador Paulo Herkenhoff em torno da trajetória e das imagens do fotógrafo-cientista. Se o trabalho de Oiticica Filho havia sido uma referência no circuito de fotoclubes do país, mas também no exterior, ele era ainda figura pouco reconhecida na comunidade artística, sendo mais frequentemente referenciado como pai do já célebre Hélio Oiticica. A relação com o filho foi inclusive uma das vias que garantiam a legitimidade do reconhecimento tardio do pai. Andreas Valentin (2017), por exemplo, coloca 
as séries abstratas Derivações (1955) e Recriações (1958), produzidas por Oiticica Filho em paralelo com os Metaesquemas, uma série de pintura realizada por seu filho, Hélio Oiticica, em 1957. Para o autor, em ambos os trabalhos residia uma inquietação em relação ao esgotamento das possibilidades do retângulo.

A chancela da Funarte ${ }^{22}$ e a assinatura de Paulo Herkenhoff, que pouco tempo depois viria a assumir a curadoria do Museu de Arte Moderna do Rio de Janeiro, parecia apontar para uma maior atenção à fotografia, sobretudo no que diz respeito à produção nacional dos 1950 e 1960. Contudo, as duas exposições não resultaram em projetos de incorporação dos acervos. O MAM carioca cria em 1986 o Departamento de Fotografia, Vídeo e Novas Tecnologias, sob a tutela de Pedro Vasquez. No ano seguinte, o museu recebe o acervo do Foto Clube Brasileiro, mediante doação de Hermínia Borges. A coleção incluía cópias fotográficas, catálogos de exposições nacionais, mas também exemplares da revista Photogramma, publicada pelo FCB entre 1926 e 1931. Este material foi a principal referência para a já citada pesquisa de Maria Teresa Bandeira de Mello (1998), publicada pela Funarte ${ }^{23}$.

Se nos anos 1960 e 1970, Thomaz Farkas teria se engajado principalmente em projetos documentais e cinematográficos, sua influência nas instituições promotoras de arte no Brasil ainda se fazia presente a partir dos anos 1980. Em São Paulo, tanto no MAM, quanto na Fundação Bienal e no MASP, Farkas foi um conselheiro influente, contribuindo decisivamente para projetos de aquisição e doação de fotografias.

Ainda na capital paulista, a coleção MASP/Pirelli foi criada em 1991 e se baseou, durante mais de uma década, num sistema de aquisição anual mediada por um conselho de especialistas, que incluía Thomaz Farkas, mas também estudiosos da história da fotografia como Rubens Fernandes Júnior e Boris Kossoy. Dedicada exclusivamente à imagem fotográfica, a coleção resultou em uma dos mais completos acervos do país. Alguns dos mais influentes fotógrafos da geração dos anos 1950 e 1960 estão presentes na coleção, tais como Geraldo de Barros, Chico Albuquerque e German Lorca. Esse processo denota o reconhecimento institucional, mas também histórico dessa geração, além de ter proporcionado um interessante jogo de interseção quando da realização das mostras. Carolina Soares (2006) destaca ainda que entre as iniciativas pioneiras e o início da coleção MASP/Pirelli é possível perceber um crescente interesse pela

22 Dehtre outras iniciativas de promoção da arte fotográfica, a Funarte foi responsável pela organização das Semanas Nacionais de Fotografias, entre 1982 e 1989.

23 Apesar da referência às cópias fotográficas pertencentes à Coleção Hermínia Borges na obra de Bandeira de Mello, atualmente o acervo do Museu de Arte Moderna do Rio de Janeiro não contacom imagens de ex-membros do FCB, à exceção de uma fotografia de Pedro Calheiros. A coleção fotográfica do período também é composta por fotografias de Stefan Rosenbaum e José Oiticica Filho. 
fotografia documental no seio da instituição. Este interesse é atestado já na década de 1970 , através dos cursos de fotografia realizados sob orientação de Claudia Andujar, e da criação do Departamento de Fotografia no museu em 1976, chefiado, em um primeiro momento, pela própria Andujar.

O MAM de São Paulo, entre os anos 1990 e 2000, construiu um acervo singular - através de doações, aquisições e comodatos - com imagens de figuras como o próprio Farkas, além dos já mencionados Cerman Lorca e Ceraldo de Barros. Foi também o MAM o palco escolhido para a sua primeira exposição individual desde 1949: Thomaz Farkas: fotógrafo, em 1997.

Em processo paralelo, por vezes, complementar, mais também suplementar, algumas instituições privadas também passaram a contar no seu acervo com imagens diretamente ligadas à geração amadora dos anos 1950 e 1960. A partir de 1995, o Instituto Moreira Salles se dedica à formação e à preservação de um acervo fotográfico ${ }^{24}$. A aquisição de grande parte da coleção dos fotógrafos Chico Albuquerque e, principalmente, Thomaz Farkas contribuiu consideravelmente para o reconhecimento artístico de ambos, tanto do ponto de vista institucional, quanto mercadológico. Em 2002, foi promovida Fotografias de Thomaz Farkas na sede da instituição no Rio de Janeiro, a primeira exposição do fotógrafo organizada pelo IMS. Já em 2011, pouco antes do falecimento do artista, o Instituto lançou a mostra Thomaz Farkas: uma antologia pessoal em São Paulo.

O acervo de obras de arte do Itaú Cultural começou a ser formado na década de 1960, e conta hoje com cerca de 12 mil itens entre pinturas, gravuras, esculturas, fotografias, filmes, vídeos, instalações, edições raras de obras literárias e outras peças que dizem respeito, exclusivamente, à história da arte brasileira. Na coleção fotográfica, o destaque fica para o acervo de imagens produzidas entre as décadas de 1940 e 1970 por antigos integrantes de fotoclubes brasileiros, com destaque para os ex-membros do Foto Cine Clube Bandeirante. A variedade, mas principalmente a qualidade das obras que compõem a coleção, deu início a uma série de exposições, iniciadas pela Realidades.Construídas: do pictorialismo à fotografia moderna, realizada em 2001 sob curadoria de Helouise Costa. Na exposição, o polo decididamente pictorialista foi formado pelas imagens da carioca Hermínia Borges; entre os modernos, os destaques são os recorrentes Ceraldo de Barros e Thomaz Farkas. Entre os dois polos, encontravam-se outros fotógrafos paulistas como José Yalenti e Eduardo Salvatore, cuja produção era marcada pela

24 Em primeiro lugar, vieram a aquisição da coleção de Cilberto Ferrez e do colecionador Pedro Corrêa do Lago. As imagens produzidas pelo antropólogo francês Claude Lévi-Straus na década de 1930 a partir da cidade de São Paulo foram adquiridas em seguida. Logo depois vieram as coleções do fotógrafo francês Marcel Gautherot, realizadas no Brasil entre as décadas de 1940 e 1980 . Atúalmente, o acervo do IMS totaliza mais de 800 mil imagens que datam, primordialmente, desde o século XIX até a década de 1980. 
diversidade de referências, passando por figuras como Ademar Manarini, Gaspar Gasparian e Cerman Lorca. A mostra ainda contou com imagens de José Oiticica Filho.

Após a primeira experiência em 2001, o Itaú Cultural realiza entre 2013 e 2014 a mostra Moderna para Sempre - fotografia modernista brasileira, com a curadoria de latã Cannabrava. Cannabrava já havia realizado duas exposições tendo como ponto de partida essa geração de fotógrafos: Mostra Fotoclubismo Brasileiro, reunindo 140 fotografias, produzidas entre 1940 e 1970 e oriundas de 30 diferentes fotoclubes do país, realizada em 2006 no Museu da Imagem e do Som em São Paulo; e Fragmentos-Modernismo na Fotografia Brasileira, que reuniu trabalhos de 24 fotógrafos ${ }^{25}$ produzidas entre as décadas de 1940 e 1950 e foi aberta ao público entre 2007 e 2008 na Galeria Bergamin. Ele também foi responsável pela curadoria, juntamente com Mônica Caldiron, da mostra comemorativa Foto Cine Clube Bandeirante - 70 anos, realizada em 2009 no Centro Cultural São Paulo.

Entre a exposição de 2001 e a de 2013, uma diferença importante: se em 2001 o número de expositores se resumia a 9 fotógrafos, em 2013 esse número alcançava a cifra de 26. Em primeiro lugar, esse fato denota o aumento material da coleção do Itaú Cultural, mas principalmente, a preferência por fotografias de inclinações modernas. Esse fenômeno é resultado da valorização histórica e institucional e sua consequente valorização no mercado contemporâneo de arte, via representação de diversas galerias. Outro exemplo fundamental é o Acervo Sesc de Arte Brasileira, mantido pela organização cível e que detém o maior acervo de positivos do fotógrafo Ceraldo de Barros, tendo promovido a coleção em diversas mostras coletivas, mas principalmente através da exposição Ceraldo de Barros e a Fotografia, organizada em parceria com o Instituto Moreira Salles em 2014.

No mesmo ano, a cessão, em regime de comodato por 50 anos, de 275 fotografias do Foto Cine Clube Bandeirante ao Museu de Arte de São Paulo, traçou as bases para um novo processo de apropriação desta geração. Diferentemente tanto das experiências monográficas que a anteciparam, quanto das mostras coletivas que ocorreram ao longo dos anos 2000 , a exposição, que contou com a curadoria da artista Rosangêla Rennó, proporcionou uma discussão mais aprofundada da experiência dessa geração de fotógrafos. Se nas montagens de latã Cannabrava, o curador já dedicava atenção à questão do intenso processo de compartilhamento de imagens que o circuito fotoclubístico proporcionava, no caso de Foto Cine Clube Bandeirante: do arquivo à rede, a atenção de Rennó se volta definitivamente para a questão do intercâmbio de fotografias.

25 Ademar Manarini, Álvaro Pereira Comes, André Carneiro, Chakib Jabor, Dalmo Teixeira Filho, Délcio Capistrano, Eduardo Enfeldt, Eduardo Salvatore, Francisco Quintas Jr., Gaspar Gasparian, Georges Radó, Geraldo de Barros, German Lorca, Certrudes Altschul, Cunter E.C. Schroeder, João Bizarro da Nave Filho, José Yalenti, Lucilio Correia Leite Jr., Osmar Peçanha, Paulo Pires, Roberto Yoshida, Rubens Teixeira Scavone, Thomaz Farkas e Tufi Kanji. 
Assim como na ocasião da participação dos bandeirantes na Bienal de São Paulo em 1953, o. ponto de partida da curadoria da mostra foram as fotografias que se acumularam nas gavetas da sede do FCCB. A principal novidade residia, no entanto, na compreensão de que aquelas fotografias não eram apenas imagens, mas objetos; elas não eram, definitivamente, bidimensionais, não cabiam em uma moldura, fixadas contra a parede. A narrativa construída por Rennó se baseou numa atenção ímpar em relação aos versos das imagens. Mas o que esses versos poderiam conter de tão fascinante? Como se tratavam de cópias realizadas pelos próprios fotógrafos entre as décadas de 1940 e 1960, os versos das imagens eram acrescidos, para além da identificação da obra, por selos e carimbos que atestam a sua participação e/ou premiação em salões no Brasil e no exterior. A própria curadora confessou, em entrevista sobre o processo de elaboração da mostra, em um primeiro momento, que pensou em expor apenas os versos das imagens, caso se tratasse de um trabalho autoral (RENNÓ, 2015).

Na montagem proposta 'por Rennó, as fotografias ganham em dimensão histórica; elas não são assimiladas apenas como um produto final, mas denotam uma complexa rede. Neste percurso, o destaque dado aos versos das imagens leva o expectador para além da fotografia e o coloca em face a um objeto: um objeto que foi criado, manipulado, transportado, exposto, admirado, reproduzido, comentado, devolvido; guardado ou novamente transportado, exposto ou recusado, admirado ou refutado, reproduzido ou não, comentado ou ignorado, devolvido ou mantido, guardado ou descartado, novamente transportado. E todo esse circuito realizado em um novo contexto, em um novo salão, com novos expectadores.

\section{Considerações finais}

Após o sucesso da exposição organizada pelo MASP em 2014, as peculiaridades do caso brasileiro entraram definitivamente no radar de instituições estrangeiras. Além das aquisições, o MoMA organizou em maio de 2017 uma jornada de estudos ${ }^{26}$ em torno da temática da fotografia brasileira de meados do século XX. O evento foi o passo inicial para a elaboração da mostra sobre a mesma temática, prevista para ser realizada no museu em 2020. A trajetória do FCCB foi tomada como ponto de partida para discutir o alcance da produção brasileira, até então negligenciada nas narrativas internacionais sobre a fotografia moderna. Inspiradas na

26 In Blackand White: Photography, Race, and the Modern Impulse in Brazilat Midcentury, realizada entre os dias 2 e 3 de maio, nas instalações do MoMA e do Graduate Center da universidade CUNY, em Nova York. 
tradição de estudos sobre o tema no Brasil, as organizadoras ${ }^{27}$ optaram por três vias de discussão: uma primeira que buscou evidenciar os elementos de distinção da fotografia moderna brasileira, principalmente na sua relação com a arte abstrata e experimental; uma segunda via destinada a relacionar a fotografia moderna a outras formas de arte marginalizadas institucionalmente; por último, a investigação do aspecto internacional dessa produção, através da rede de fotoclubes criadas, suas exposições e publicações. Além disso, foi possível perceber o interesse, tanto dos responsáveis do museu, quanto dos pesquisadores estrangeiros, por alguns elementos específicos: o fator imigração, na medida em que imigrantes e filhos de imigrantes representavam uma grande parcela dos membros do clube paulistano; racial, através da ausência e/ou presença da representação de figuras afrodescendentes ou da cultura afrobrasileira; de gênero, representação do corpo feminino e a trajetória de mulheres fotógrafas no período. Outra importante pista sobre a abordagem museu considera empreender sobre seu acervo de fotografias brasileiras é a presença de uma série de nove imagens de Certrudes Altschul na mostra Making Space: Women Artists and Postwar Abstraction, organizada pelo MoMA entre abril e agosto de 2017. O trabalho de Altschul, que se tornou membro do FCCB em 1952, foi definido como "experimentações com processo e forma, e composições inventivas descobertas no cotidiano"28. Suas fotografias foram alocadas na seção "Abstração geométrica" da mostra, ao lado de artistas brasileiras como Lygia Clark e Lygia Pape, além da venezuelana Cego.

A Société Française de Photographie, por sua vez, organizou entre junho e outubro de 2016, na galeria Chambre Claire em Rennes, a exposição Brésil - France-Brésil: Photographie et abstraction, 1957-796029. Realizada a partir do acervo da própria insituição, a mostra atesta para a popularidade da temática da abstração em fotografia. A coleção de fotografias brasileiras da SFP formada por imagens expostas pela instituição em 1951 e 1960 -também é o ponto de partida para a realização da mostra Images voyageuses: photographie brésilienne en France ${ }^{30}$, em cartaz entre outubro e novembro de 2017 na Fundação Calouste Culbenkian em Paris. Diferentemente da primeira iniciativa, Images voyageuses, em sintonia com a proposta de Rosângela Rennó no MASP, centra sua abordagem no circuito de partilha de imagens em que essas imagens permaneceram associadas, tentando apreender os alcances e limites das trocas empreendidas.

Apesar do sucesso que alcançaram nas décadas de 1950 e 1960, essas imagens permaneceram guardadas por décadas: Assim como no caso das imagens expostas no MASP em 2014, cedidas em comodato pelo FCCB, elas são sobreviventes. Ao lado dessas, estão aquelas que alcançaram

27 Sarah Meister e Abigail Lapin Dardashti.

28 Texto de parede da mostra. Tradução livre do trecho "Experimentations with process and form, and inventive compositions discovered within every daylife".

29 Curadoria de Luce Lébart.

30 Curadoria de Lucas Mendes Menezes e Marion Perceval. 
a longevidade através da iniciativa de fotógrafos e familiares que, na maioria das vezes através recursos próprios, preservaram suas coleções pessoais. Elas venceram um hiato que perdurou anos e que, em consequência, envolveu uma perda inestimável de cópias fotográficas, negativos e publicações, coleções inteiras que não encontraram o mesmo destino das mencionadas anteriormente. Desta forma, talvez o principal legado desse processo de revalorização dessa geração de fotógrafos brasileiros ${ }^{31}$ seja o interesse pela descoberta de novos acervos. Por outro lado, há também uma tendência à supervalorização dos aspectos "modernos" das fotografias recuperadas. Além da tentação em descontextualizar as imagens, negligenciado as condições de produção, circulação e apropriação a que elas estiveram associadas, existe também o risco de imputar a essas fotografias elementos estéticos, políticos e sociais que nunca fizeram parte da realidade dos seus autores.

\section{Referências}

BARROS, Geraldo. A sala de Fotografia. Boletim [Foto Cine Clube Bandeirante], São Paulo, n. 87, p. 12 , mar./abr. 1954.

BOLETIM. Foto Cine Clube Bandeirante: São Paulo, n. 9, jan. 1947.

BOLETIM. Foto Cine Clube Bandeirante: São Paulo, n. 23, mar. 1948.

BOLETIM. Foto Cine Clube Bandeirante: São Paulo, n. 38, jun. 1949.

BOLETIM. Foto Cine Clube Bandeirante: São Paulo, n. 49, maio 1950, p. 7.

BOLETIM. Foto Cine Clube Bandeirante: São Paulo, n. 54, out. 1950.

BOLETIM. Foto Cine Clube Bandeirante: São Paulo, n. 87, mar./abr. 1954.

FOTO CLUBE DO ESPÍRITO SANTO. IV Salão Capixaba de Arte Fotográfica, Vitória, 1951.

FOTO-CINE CLUBE DO RECIFE. II Salão Nacional de Arte Fotográfica, Recife, 1955.

COSTA, Helouise; RODRICUES, Renato. A fotografia mioderna no Brasil. Rio de Janeiro: UFR]; Iphan; Funarte, 1995.

31 Um dos exemplos mais recentes diz respeito ao acervo do fotógrafo amador mineiro Wilson Baptista. Entre maio e junho de 2017, a Galeria Periscópio, de Belo Horizonte, organizou uma mostra a partir do acervo de Baptista. A exposição representou um recorte do acervo de mais de 7 mil negativos atualmente gerenciado pela galeria. Baptista foi um dos membros fundadores e ex-presidente do Foto Clube de Minas Cerais, agremiação ativa em Belo Horizonte entre 1951 e meados da década de 1960. 
Fotografia, Arte e História

Artigos e Ensaios

na atualidade: relações praticadas

DOI: 10.20396/resgate.v26i2.8650362

DOBRANSZKY, Diana. A legitimação da fotografia no museu: o Museum of Modern Art de Nova York e os anos Newhall no Departamento de fotografia. Tese (Doutorado em Multimeios) - Universidade Estadual de Campinas, Campinas. 2008.

GINZBURG, Carlo. Mitos, emblemas, sinais: morfologia e historia. São Paulo: Companhia das Letras, 1991.

MASCLET, Daniel. Le 35 Salon International d'Art Photographique de Paris. Photo-Cinéma, Paris, p. 157, nov. 1947.

XXXIX Salon International de Paris. Photo-Cinema, Paris, p. 249, out. 1951.

MEISTER, Sarah. A trajetória da fotografia brasileira no MoMA. SP-arte, São Paulo, 6 jun. 2016. Disponível em: <http://www.sp-arte.com/foto/noticias/a-trajetoria-da-fotografia-brasileira-no-moma-por-sarah-meister/>. Acesso em: 15 ago. 2017.

MELLO, Maria Teresa Bandeira de. Arte e Fotografia: o movimento pictorialista no Brasil. Rio de Janeiro: Funarte, 1998.

NEWHALL, Beaumont. The History of Photography: from 1839 to the present day. New York: The Museum of Modern Art, 1949.

PHOTOGRAMS OF THE YEAR. Royal Photographic Society: Londres, 1953.

RENNÓ, Rosângela. Foto cine clube bandeirante: do arquivo à rede. Museu de Arte de São Paulo Assis Chateaubriand, São Paulo, 2015. Disponível em: <http://masp.art.br/masp2010/exposicoes integra. php?id=254\&periodo_menu=>. Acesso em: 23 abr. 2016.

Foto Cine Clube Bandeirante no MASP: entrevista com a curadora Rosângela Rennó. Revista Zum, São Paulo, 8 dez. 2015. Disponível em: <https://revistazum.com.br/radar/fccb-masp-entrevista-rosangela-renno/>. Acesso em: 17 ago. 2017

SOARES, Carolina Coelho. Coleção Pirelli-MASP de fotografia: fragmentos de uma memória. Dissertação (Mestrado em Artes Plásticas) - Universidade de São Paulo, São Paulo. 2006.

VALENTIN, Andreas. Nas asas da mariposa: exibindo a obra de José Oiticica Filho. Studium, Campinas, n. 32, 2011. Disponível em: <http://www.studium.iar.unicamp.br/32/2.html>. Acesso em: ago. 2018.

116

Resgate-Rev. Interdiscip. Cult., Campinas, v. 26, n. 2 [36], p. 99-116, jul./dez. 2018-e-ISSN: 2178-3284 